\title{
Maximum Power Control of IPMSM Considering Nonlinear Cross-Magnetization Effects
}

\author{
Youn-Hyun Kim*, Won-Kyu Kim** and Sol Kim ${ }^{\dagger}$
}

\begin{abstract}
Interior permanent magnet synchronous motor is widening its application compared to other AC machines because of magnetic and reluctance torque. Despite of the advantages, improving control performance with parameter nonlinearity consideration is crucial during the field weakening control. This paper shows a maximum power control method at the field weakening region that considers $d, q$ inductance's nonlinearity due to magnetic saturation and $d, q$ mutual inductance. To verify the feasibility of control scheme, FEM simulations and experiments about comparison between linear and nonlinear maximum power control are carried out.
\end{abstract}

Keywords: Maximum power control, Cross magnetizing effect, Interior permanent magnet synchronous motor (IPMSM).

\section{Introduction}

Interior permanent magnet synchronous motor (IPMSM) has numerous advantages which are high torque per current, high output per weight, negligible noise, and outstanding structural durability. Thanks to these advantages IPMSMs are widening its application compared to other $\mathrm{AC}$ machines. Not only high torque is generated from a small rotor size but also a wide range of variable speed is attained through field weakening control because the IPMSM both have reluctance torque and magnetic torque which are generated due to the difference of $d, q$ inductances [2,3].

Despite of the advantages of IPMSM stated above, technical difficulties in terms of determining parameter values and control algorithm due to complicated structure and control system leaves IPMSMs still a challenge worthy machine. Especially, improving control performance with parameter nonlinearity consideration is crucial during the field weakening control [4].

Vector control of IPMSM were utilized by inducing the $d, q$ command current based on the stator's voltage equation according to the IPMSM's field weakening control research reports in the 1990s [5, 6]. Although, the field weakening control method made a significant contribution to establishing the basic field weakening theory, it requires an accurate value of $d, q$ inductance for its high performance use. Also, it is based on the linear model which only considers constant $d, q$ inductances that does not take magnetic flux nonlinearity or mutual inductance into consideration. Thus, control performance hinders when the model diverges from the physical system,

$\dagger$ Corresponding author: Dept. of Electrical Engineering, Yuhan College, Korea. (slamsol@yuhan.ac.kr)

* Dept. of Electrical Engineering, Hanbat University, Korea. (yhyunk@hanbat.ac.kr)

** Daedong Movel System Co. Ltd, Korea. (wkkim@ddmvs.co.kr)

Received: February 9, 2012; Accepted: July 3, 2012 and high efficient performance is not being achieved at all operation range due to the neglected nonlinearity of the $d$, $q$ inductance. Moreover, field weakening control studies that considered magnetic saturation did not as well considered the mutual inductance and linearized the $d, q$ inductances independently [7]. Later in the 2000s, papers that analyzed the influence of $d, q$ mutual inductance and $d$, $q$ inductance variation due to magnetic saturation have been published [8,9]. Meanwhile, online parameter estimation, self-tuning control, online optimized field weakening algorithm, fuzzy logic algorithm, and nonlinear controller, were proposed, however; these partially require motor parameters and possess complicating algorithms and hard access to applications because they are yet limited to maximum torque per ampere (MTPA) control [10-14]. Also, methods which determine current command values based on the voltage of the outer voltage loop and the measured DC link voltage were proposed. Although this method has the advantage that it does not require the motor parameter, DC link voltage is required, the response according to the load fluctuation is slow, and has a low stability [3].

Therefore, this paper proposes a maximum power control method at the field weakening region that considers $d, q$ inductance's nonlinearity due to magnetic saturation and $d, q$ mutual inductance. In order to realize the proposition, the FEM which will later yield the $d, q$ inductance will be used to analyze the nonlinearity of the $d$, $q$ inductance. In addition, the results will be confirmed through experiments. Simplified control model which is based on the attained nonlinear inductances makes the algorithm easier to be realized. Also, control model that calculated based on the simplified with non-linear inductance parameters enables field weakening control algorithm to be easy, and proposed control algorithms were verified with comparison of the linear control system through the performance current, voltage, and output characteristics that realize the maximum power control in 
the field weakening area. In the study, we will verify the effect of the non-linear $d, q$ inductances on driving performance. To prove the method proposed, we will experiments an actual IPSM and a specific control drive we made, as well as perform a simulation.

\section{IPMSM}

\subsection{Specification of IPMSM model}

$\mathrm{NdFeB}$ is used for interior permanent magnet of IPMSM. The length of the permanent magnet is decided to be less than half of a barrier in order to maximize the effect of field weakening control in the constant power region. IPMSM has 4 poles, 24 slots, 3 phase parallel star connection, and distributed winding. A half of cross section of IPMSM is shown in Fig. 1 and Table 1 describes a specification. Parameters of the linearized IPMSM on a rated operating point are shown in Table 2.

Fig. 2 shows $L_{d}$ and $L_{q}$ inductance profiles, which are calculated by nonlinear finite element analysis considering cross magnetization. Since $L_{d}$ and $L_{q}$ inductances are strongly influenced by both $I_{d}$ and $I_{q}$ currents, a drive system should consider the variation of inductance with currents. To verify the reliability of the calculated inductance profile, torque simulation compared with the test in Fig. 3. The torque simulation and the test results are matched up with the current condition of $6[\mathrm{~A}]$ so that the inductance profiles are reliable.

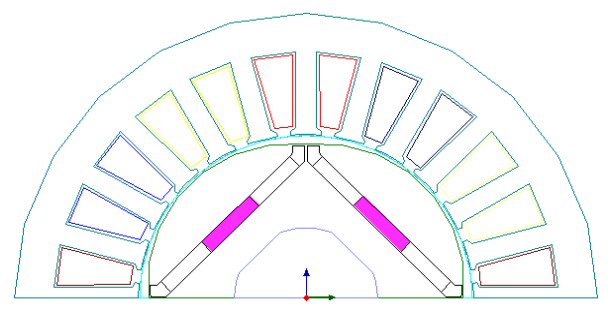

Fig. 1. A half of cross section of IPMSM

Table 1. Specification of IPMSM

\begin{tabular}{c|c|c|c}
\hline Item & Value & Item & Value \\
\hline Diameter of stator & $60.9[\mathrm{~mm}]$ & Numbers of Pole & 4 \\
\hline Stack Length & $60[\mathrm{~mm}]$ & Turns & $40[$ turns $]$ \\
\hline Air Gap & $0.6[\mathrm{~mm}]$ & Rated Voltage & $80[\mathrm{~V}]$ \\
\hline Material of PM & NdFeB & Rated Power & $0.8[\mathrm{~kW}]$ \\
\hline Width of PM & $14[\mathrm{~mm}]$ & Rated Speed & $3,600[\mathrm{rpm}]$ \\
\hline
\end{tabular}

Table 2. Parameter of the linearized IPMSM

\begin{tabular}{c|c|c}
\hline Item & Symbol & Value \\
\hline Pole pair & $P_{n}$ & 2 \\
\hline Flux linkage by PM & $\Phi_{a}$ & $0.123038[\mathrm{~Wb}]$ \\
\hline$d$-axis inductance & $L_{d}$ & $12[\mathrm{mH}]$ \\
\hline$q$-axis inductance & $L_{q}$ & $21[\mathrm{mH}]$ \\
\hline Armature resistance & $R_{a}$ & $0.469[\Omega]$ \\
\hline Equivalent resistance of core loss & $R_{c}$ & $300[\Omega]$ \\
\hline
\end{tabular}

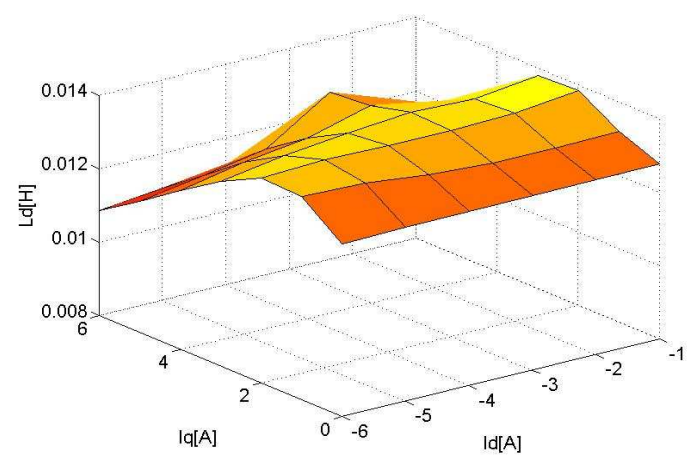

(a) $L_{d}$ inductance profile

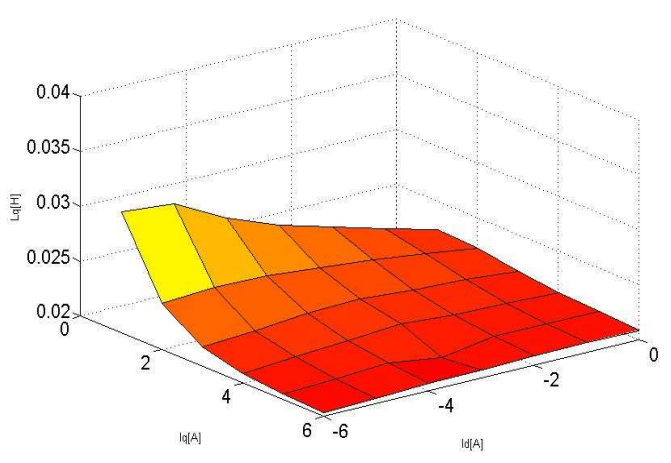

(b) $L_{q}$ inductance profile

Fig. 2. $L_{d}$ and $L_{q}$ inductances considering the cross magnetization

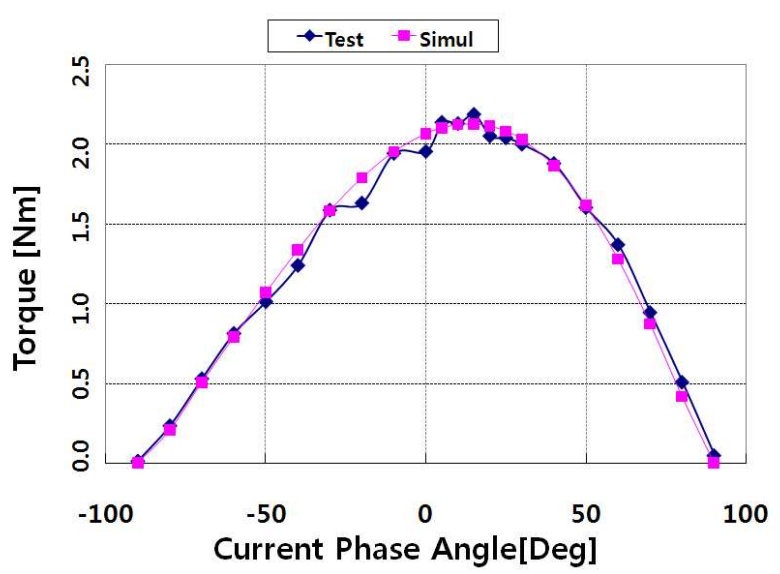

Fig. 3. Torque profile according to a current angle

\subsection{IPMSM drive controller}

Fig. 4 shows a block diagram of an IPMSM drive controller to test the proposed control scheme. The drive controller is made up of 3 phase PWM inverter, maximum power controller, current controller, and encoder. Control variables are monitored through $\mathrm{D} / \mathrm{A}$ converter of control board in real time. TI DSP TMS320F2811 takes a role of main CPU. A control board and a power module are shown in Fig. 5. 


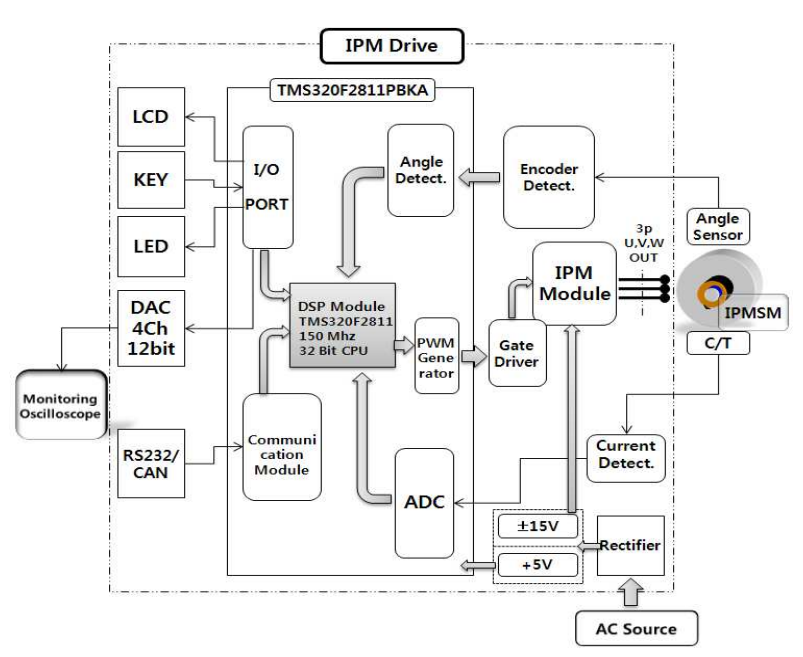

Fig. 4. A block diagram of IPMSM drive controller

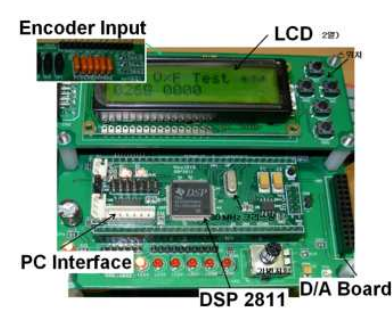

(a) DSP controller

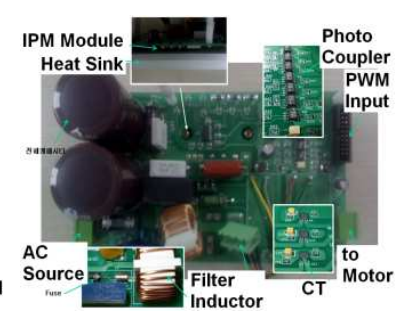

(b) IPM Power Stack
Fig. 5. A drive controller of IPMSM

\section{Proposed Maximum Power Control System}

\subsection{Maximum power drive condition in the field weakening region}

IPMSM operation refers to the locus of MTPA in the constant torque region; however, in the constant output region where speed exceeds $\omega_{\text {base, }}$ the current and voltage limit of the inverter exists as in Eqs. (1), (2).

$$
\begin{gathered}
i_{d}^{2}+i_{q}^{2} \leq I_{a m}^{2} \\
\left(L_{d} i_{d}+\Psi_{a}\right)^{2}+\left(L_{q} i_{q}\right)^{2} \leq\left(\frac{V_{o m}}{\omega}\right)^{2}
\end{gathered}
$$

The two equations above are plotted above as Fig. 6 . The inner area of the circle which is determined by $I_{a m}$ is the range of the current limit and is constant regardless of speed. However, it is obvious that the voltage limit locus shrinks as the speed grows and that the maximum output operating points are established based on the intersection of the current limit locus and the voltage limit locus. In other words, the operating point moves through A, B, and $\mathrm{C}$ corresponding to the speed growth. The thesis implemented two different types of maximum power control referred to the base speed by using the MTPA and the Field Weakening Control as follows. In low speed

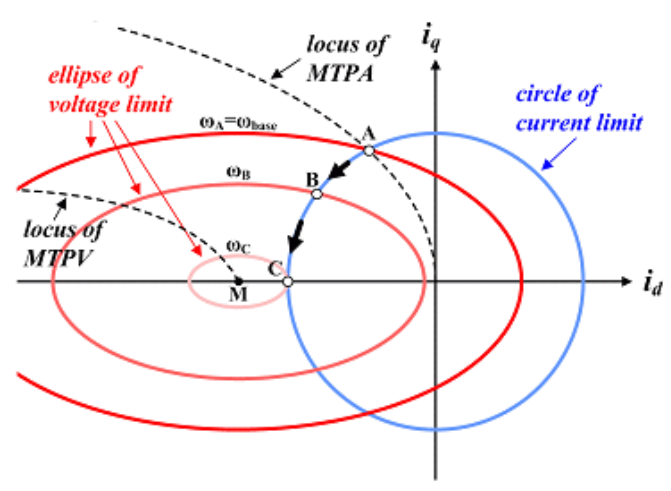

Fig. 6. Current and voltage locus according to speed growth in maximum power control

region where sufficient voltage margin is present, the MTPA control which only takes the current limit into consideration is implemented; however, in speed region above the base $\operatorname{speed}\left(\omega_{\text {base }}\right)$, the intersection of the current and the voltage limit locus is utilized to conduct field weakening control as in Eqs. (3), (4). In this mode of operation the current and voltage exists within the range of $I_{a m}, V_{o m}$.

$$
\begin{gathered}
i_{d}=\frac{\Psi_{d} L_{d}-\sqrt{\left(\Psi_{d} L_{d}\right)^{2}+\left(L_{q}^{2}-L_{d}^{2}\right)\left(L_{q} I_{a m}\right)^{2}-\left(\frac{V_{o m}}{\omega}\right)^{2}}}{L_{q}^{2}-L_{d}^{2}} \\
i_{q}=\sqrt{I_{a m}^{2}-i_{d}^{2}}
\end{gathered}
$$

However, Eqs. (3), (4) are composed of constant $d, q$ inductance that nonlinear cross magnetizing effect cannot be estimated. Thus, the thesis suggests a method which yields $d, q$ current command by utilizing nonlinear cross magnetization $d, q$ inductances that alter according to input current magnitude and phase.

\subsection{Suggested maximum power control}

Maximum power controller configuration and control flowchart of IPMSM are depicted in Fig. 7 and 8. Since the rated max current of IPMSM is 6[A], $I_{a m}$ commands 6[A]. The controller conducts decoupled $d, q$ current controlled command so that the motor operates in the MTPA mode below $\omega_{\text {base }}$ and in the maximum output power mode above the $\omega_{\text {base }}$ referring to the encoder based speed sensor values. Since this paper concentrates on the enhanced performance of maximum output in the field weakening region, the MTPA control is conducted based on the conventional linear type. The maximum power control current command is obtained as in Eqs. (8), (9) via $L_{d}, L_{q}$ inductances which are extracted from the cross magnetization considered FEM analysis.

Field weakening control $d, q$ current command is the function of $I_{a m}, \omega . I_{d}, I_{q}$ corresponding to $I_{a m}$ and $\omega$ has been yielded based on $L_{d}, L_{q}$ that are obtained through cross magnetization consideration. This paper is based on 6[A] $I_{a m}$ maximum power control and thus Eq. (5) can be rewritten as in Eq. (6). 


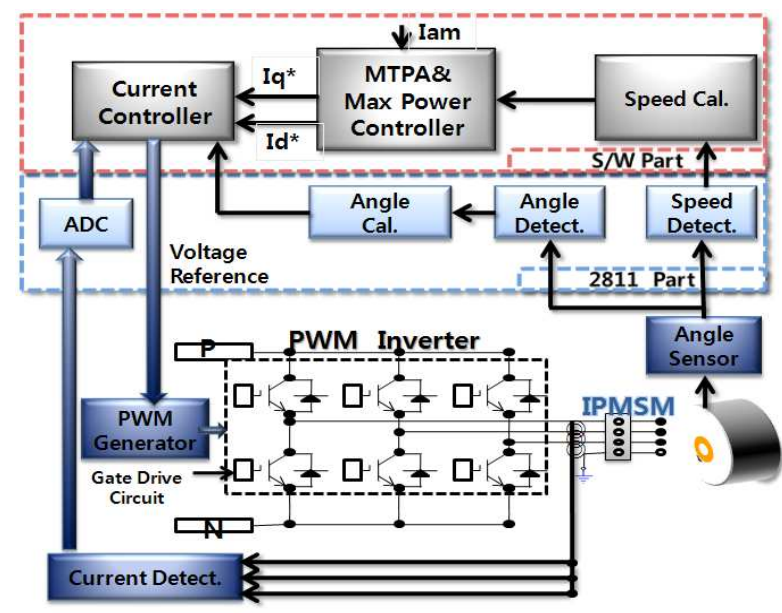

Fig. 7. IPMSM Driver Configuration

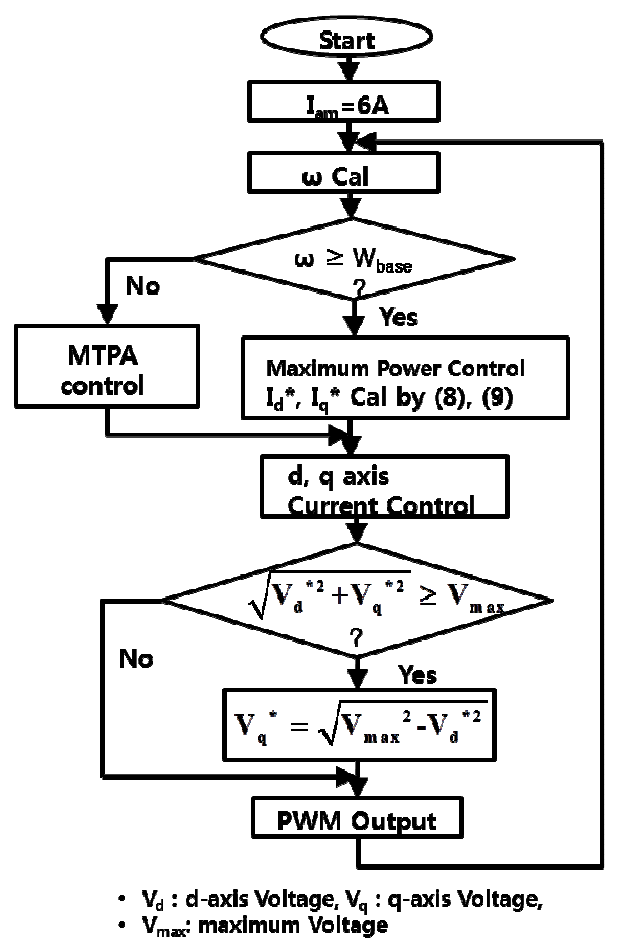

Fig. 8. IPMSM Maximum power controller Flowchart

$$
\begin{aligned}
& f\left(I_{a m}, \omega\right)=\sum_{i=1}^{n 1}\left(\prod_{i \neq \mathrm{k}} \frac{I_{a m}-I_{a m k}}{I_{a m i}-I_{a m k}}\right) \cdot f\left(I_{a m i}, \omega\right) \\
& f\left(I_{a m 1}, \omega\right)=\sum_{j=1}^{n 2}\left(\prod_{j \neq \mathrm{s}} \frac{\omega-\omega_{s}}{\omega_{j}-\omega_{s}}\right) \cdot f\left(I_{a m 1}, \omega_{j}\right)
\end{aligned}
$$

Eqs. (7), (8) is yielded by substituting and 3D interpolating $6[\mathrm{~A}]$ for $I_{a m l}$. The constants are as in Table 3.

$$
\begin{gathered}
I_{d}^{*}=I_{d 0}+I_{d 1} \omega+I_{d 2} \omega^{2}+I_{d 3} \omega^{3} \\
I_{q}^{*}=I_{q 0}+I_{q 1} \omega+I_{q 2} \omega^{2}+I_{q 3} \omega^{3} \\
I_{d}^{*}=\sqrt{I_{a m}^{2}-i_{a}^{* 2}}
\end{gathered}
$$

Table 3. Interpolation Constants

\begin{tabular}{c|c||c|c}
\hline Constants & Value & Constants & Value \\
\hline $\mathrm{I}_{\mathrm{d} 0}$ & 4.715 & $\mathrm{I}_{\mathrm{q} 0}$ & 10.898 \\
\hline $\mathrm{I}_{\mathrm{d} 1}$ & $-4.9 \mathrm{E}-3$ & $\mathrm{I}_{\mathrm{q} 1}$ & $-3.7 \mathrm{E}-3$ \\
\hline $\mathrm{I}_{\mathrm{d} 2}$ & $7.71 \mathrm{E}-7$ & $\mathrm{I}_{\mathrm{q} 2}$ & $5.71 \mathrm{E}-7$ \\
\hline $\mathrm{I}_{\mathrm{d} 3}$ & $-4.05 \mathrm{E}-11$ & $\mathrm{I}_{\mathrm{q} 3}$ & $3.3 \mathrm{E}-11$ \\
\hline
\end{tabular}

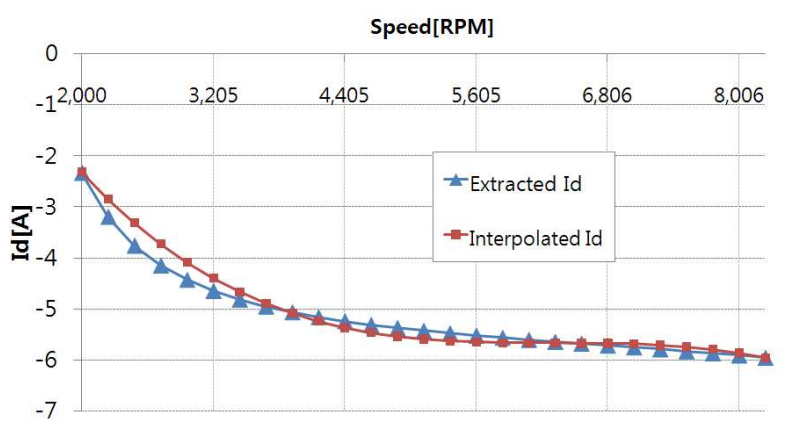

Fig. 9. $I_{d}$ analysis based Interpolated and Extracted values

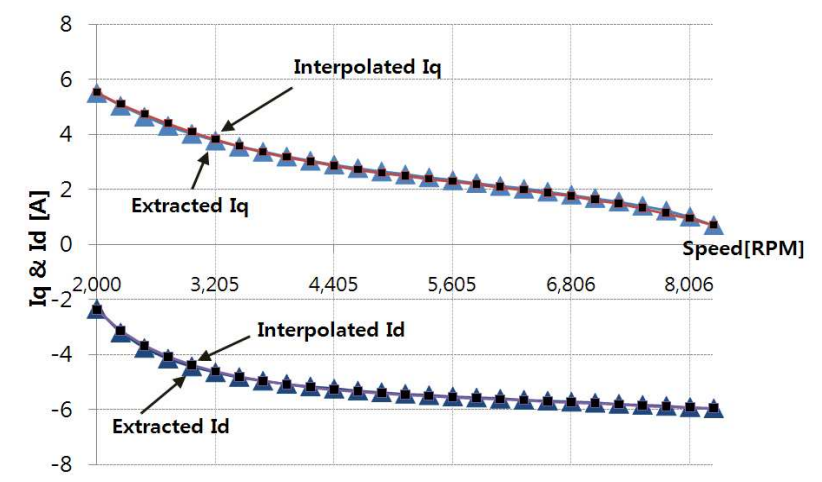

Fig. 10. $I_{d}, I_{q}$ analysis based Interpolated and Extracted values

Fig. 9 is a comparison of cross magnetization considered $I_{d}$ and $I_{d}$ referred to the interpolation of Eq. (7). The first waveform of Fig. 10 is a comparison of $I_{q}$ referred to the interpolation of Eq. (8) and the cross magnetization considered $I_{q}$. It is obvious that it has a significantly smaller error than $I_{d}$, and thus, by yielding $I_{d}$ through Eq. (9), the error is significantly reduced as seen in the second Fig. in Fig. 10. Therefore, this paper exploited Eq. (8) and (9).

\section{Simulation Result of Maximum Power Control}

\subsection{Simulation result}

The characteristics of nonlinear maximum power control has been analyzed and the results are shown in Fig. 11 and 12. Voltage limit has been set lower than the rated voltage to $60[\mathrm{~V}]$ by considering the test inverter output voltage margin. Accordingly, the $\omega_{\text {base }}$ has been set to be $2700[\mathrm{rpm}]$.

Fig. 11 and 12 are a comparison of fixed inductance 
Maximum Power Control of IPMSM Considering Nonlinear Cross-Magnetization Effects

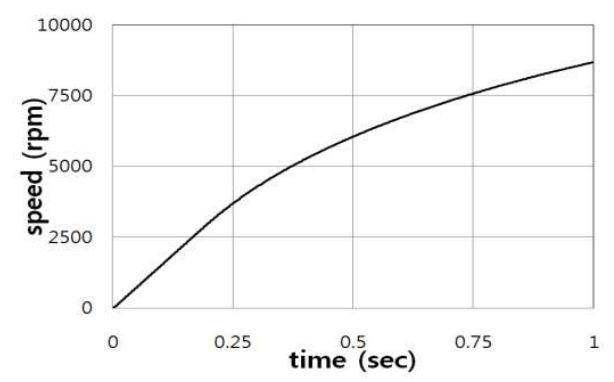

(a) Speed

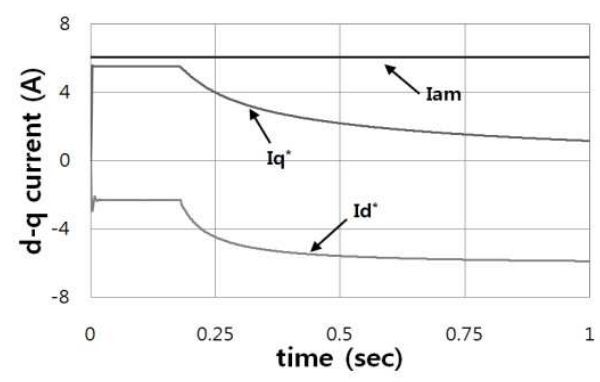

(b) Current

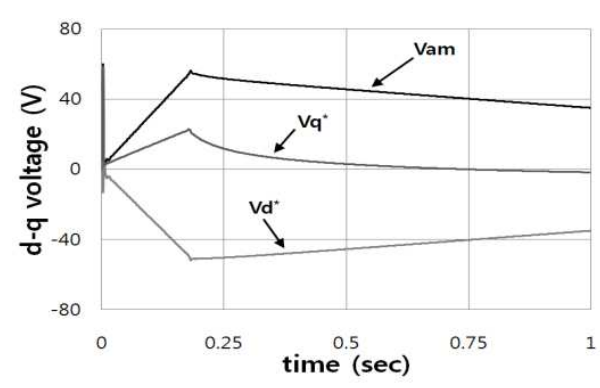

(c) Voltage

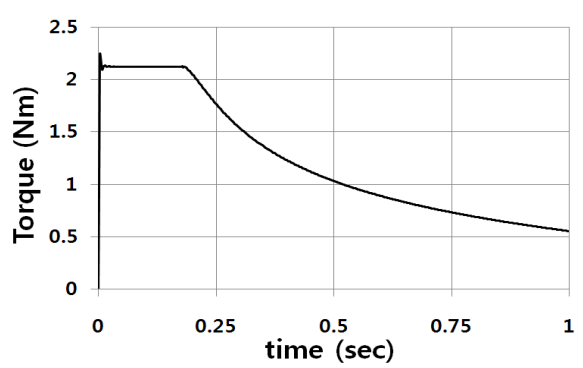

(d) Torque

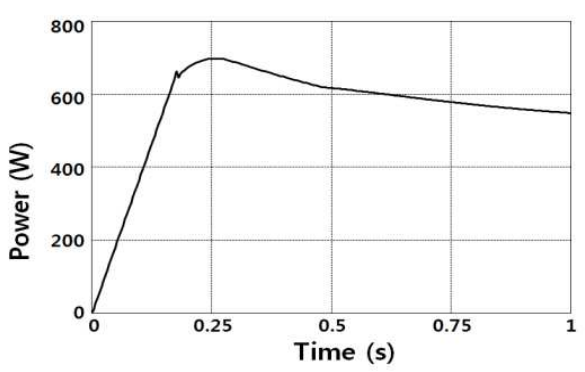

(e) Output

Fig. 11. Linear maximum power control

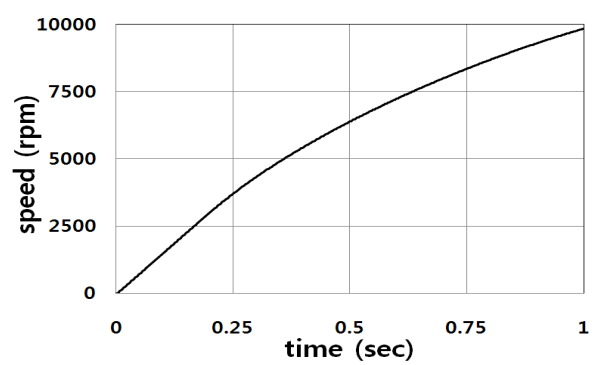

(a) Speed

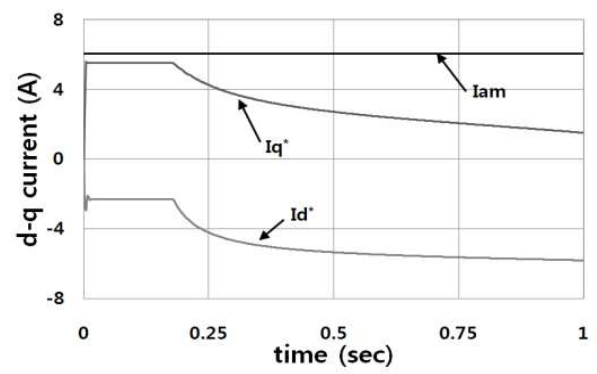

(b) Current

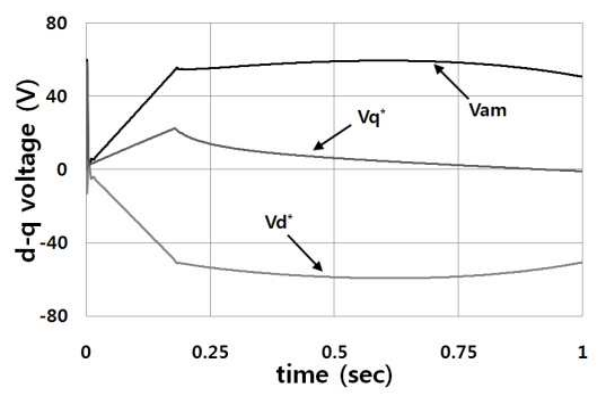

(c) Voltage

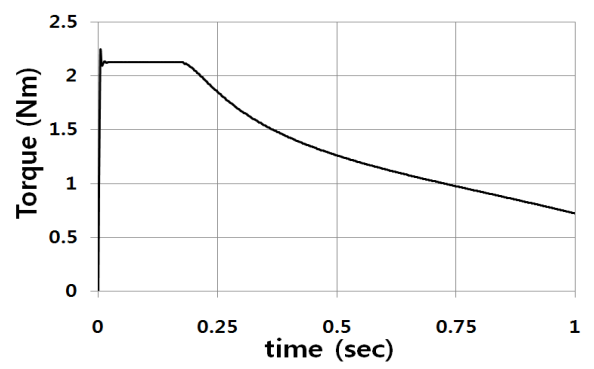

(d) Torque

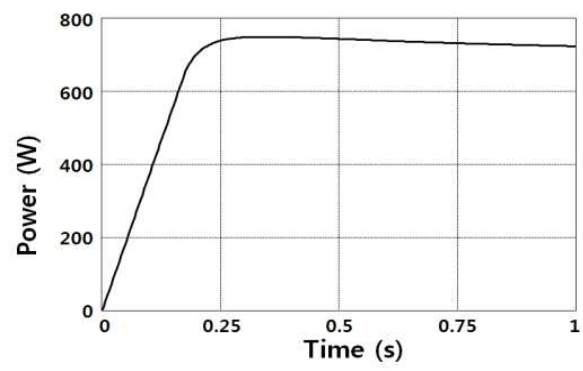

(e) Output

Fig. 12. Nonlinear maximum power control 
based linear output control and cross magnetization considered nonlinear maximum power control simulation operation characteristic. The figure exhibits that transition from MTPA to constant output perfectly occur at 2700 [rpm] and 0.17[sec]. Fig. 11(a) and 12(a) show linear and nonlinear control speed profile, and Fig. 11(d) and 12(d) show the torque profile. According to Fig. (a) and (d), we can learn that nonlinear maximum power control has a wider range of speed characteristics than the linear maximum power control.

Both Fig. (b)s show the linear and nonlinear control current waveform respectively, Fig. (c) shows the voltage waveform. Because the Fig. (c)'s voltage characteristic of linear output control is based on the constant inductance, optimal $d, q$ current is not present and thus not maximizing the usage of voltage limit. However, the nonlinear output control operates near voltage limit and capable of broad operation than the linear control.

Fig. (e) shows the output waveform which reduces in the linear maximum power control mode and maintain constant output in the nonlinear maximum power control mode.

Fig. 13 is a comparison between linear and nonlinear maximum power control with respect to current and torque waveform at different speed. We can conspicuously learn that nonlinear maximum power control possess a wider

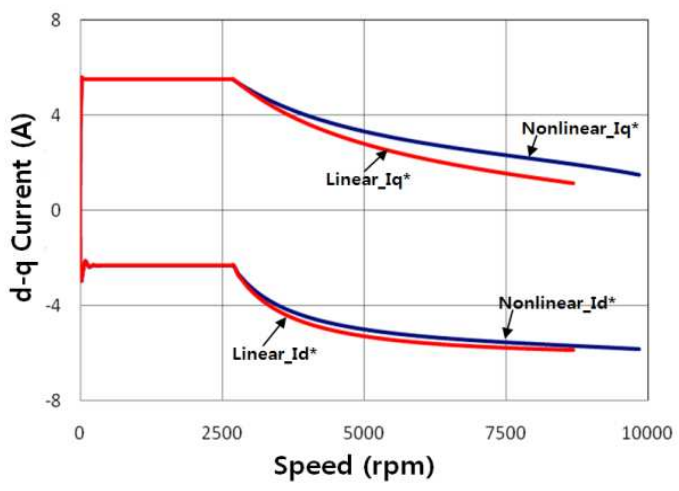

(a) Current according to speed

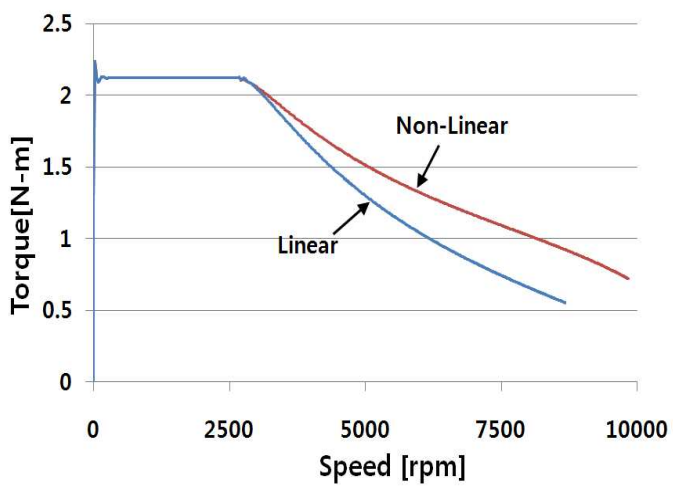

(b) Torque according to speed

Fig. 13. Linear and nonlinear maximum power control performance comparison simulation operation range. From the results of the simulation above, we can learn that linear control cannot satisfy an optimal operation with proper values of $I_{d}, I_{q}$, and that cross magnetization should be considered to enhance the performance.

\subsection{Test result}

The actual IPMSM model analysis has taken place based on the simulation results. Fig. 14 and 15 are the comparison between linear and nonlinear maximum power control. $V_{a m}$ is limited to $60[\mathrm{~V}]$, and $\omega_{\text {base }}$ is $2700[\mathrm{rpm}]$. As we have seen from the simulation results, transition from MTPA to maximum power control is fulfilled in the actual IPMSM model as well.

Fig. 14(a) and 15(a) show the speed waveform for the linear and nonlinear control. As from the simulation results the actual test results show that the nonlinear control saturates $1,000[\mathrm{rpm}]$ higher point then the linear control saturation point. Fig. (b) shows a current characteristic

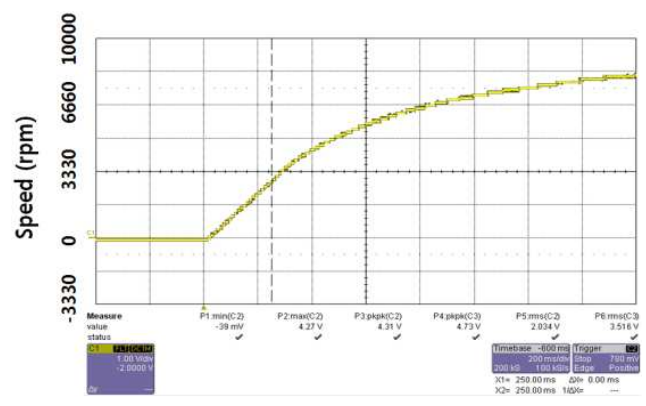

(a) Speed

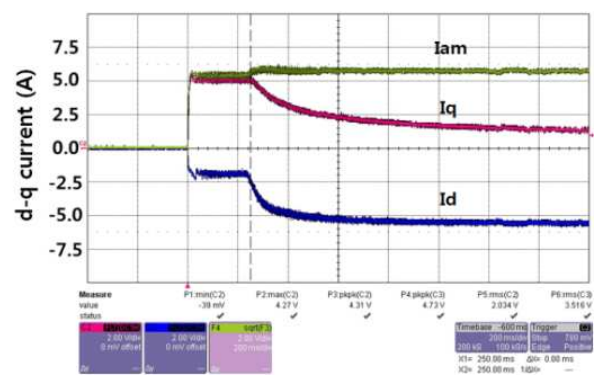

(b) Current

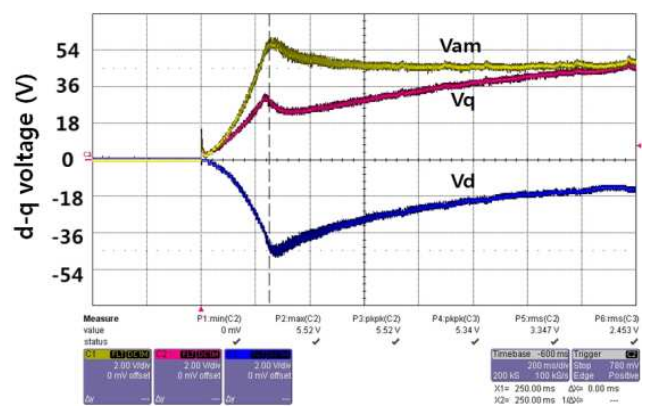

(c) Voltage

Fig. 14. Linear Maximum Power Control 


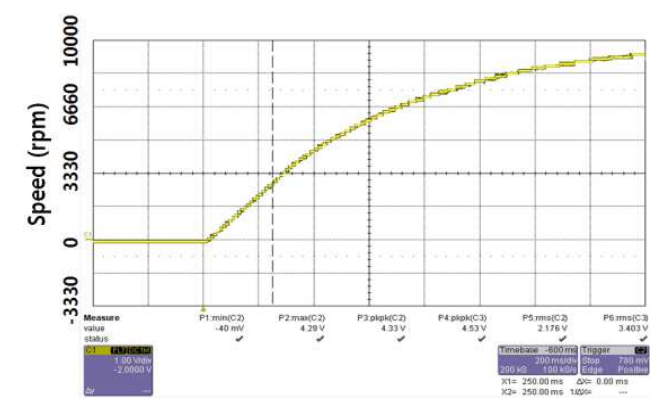

(a) Speed

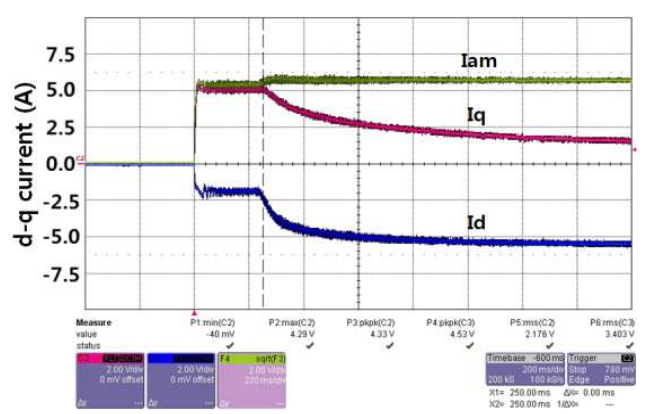

(b) Current

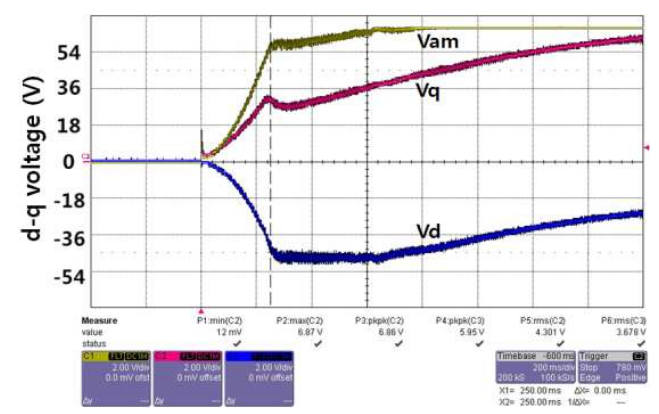

(c) Voltage

Fig. 15. Nonlinear Maximum Power Control

with a slight distinction at the transition from the MTPA control to the maximum power control which is presumed to have been generated from the truncation error while the calculating the $I_{d}, I_{q}$. Moreover, $I_{q}$ has a bigger value at nonlinear control, and $I_{d}$ has a smaller value at nonlinear control according to Fig. (b). Although the difference doesn't seem to be significant in Fig. (b), it is obviously different when compared in the speed domain as in Fig. 15. According to Fig. 16(b), the nonlinear control has a greater torque and a wider range of operation than the linear control. The torque was measured with HBM's T20WN/ $50 \mathrm{NM}$.

Fig. 14(c) and 15(c) show the voltage characteristic; from the top to bottom, max voltage: $V_{a m}, q$-axis voltage: $V_{q}, d$-axis voltage: $V_{d}$. Linear control cannot operate with optimal $d, q$ current as well as cannot utilize the max voltage limit as in the simulation. Although the nonlinear control has a better performance than the linear control, the need for enhancement exists in the nonlinear control since

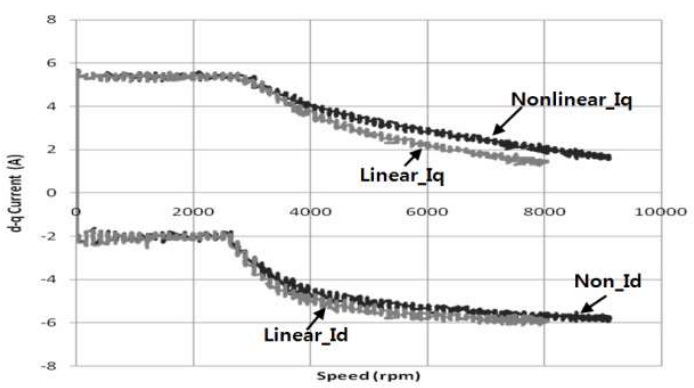

(a) Current According to Speed

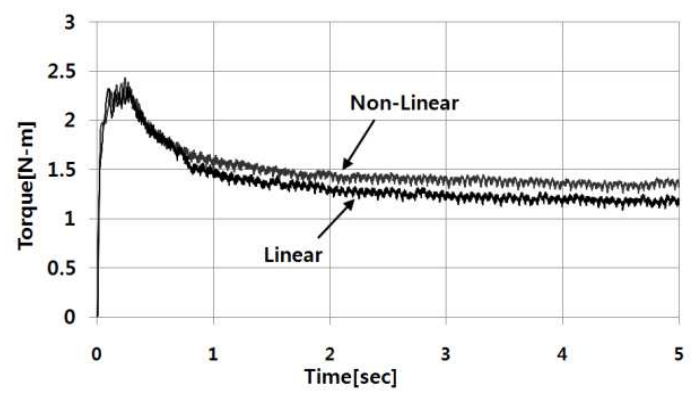

(b) Torque According to Time

Fig. 16. Comparison between Linear and Nonlinear Maximum Power Control

it does not have a perfect current command and so has an error upon transition from MTPA to maximum power control.

We have confirmed that the nonlinear control has a wider range of operation than the linear control via actual IMPSM model test, as well as, that cross magnetization considered nonlinear maximum power control is necessary for control enhancement.

\section{Conclusion}

This paper dealt with the algorithm for maximum power control in the field weakening region considering cross magnetization. To verify feasibility of proposed algorithm, voltage, current, torque and power of the nonlinear maximum power control are compared with the linear maximum power controls within simulation and experiment. The effect of operation characteristic influenced by cross magnetization is investigated.

This paper showed that the linear maximum power control ignoring nonlinearity of $d, q$ inductances runs narrow operation range because non-optimal $I_{d}$ and $I_{q}$ mislead low torque and power in the field weakening region. On the other hand, nonlinear maximum power control considering cross magnetizing effect increases torque and power and works with wide operation range. It is necessary to apply nonlinear maximum power control in order to operate IPMSM in the filed weakening region. 
Nonlinear maximum power control can help increasing output power range of IPMSM.

\section{References}

[1] M. Nasir Uddin, Tawfik S. Radwan, M. Azizur Rahman, "Performance of Interior Permanent Magnet Motor Drive Over Wide Speed Range," IEEE Trans. Energy Conversion, Vol. 17, No. 1, pp. 79-84, Mar. 2002.

[2] Min-Seok Kim, Sang-Yeop Kwak, Hyun-Kyo Jung, Sang-Yong Jung, "D-Q Flux Linkage Identification for Interior Buried Permanent Magnet Synchronous Motor considering Cross-Magnetization," Trans. KIEE, Vol. 56, No. 12, pp. 2116-2121, Dec. 2007.

[3] Jang-Mok Kim, Seung-Ki Sul, "Outer Voltage Regulation Loop for Maximum Torque Operation of Interior Permanent Magnet Synchronous Motor in the Flux Weakening Region," Trans. KIEE, Vol. 56, No. 12, pp. 2116-2121, Jul. 1998.

[4] Ki-Chan Kim, "A Study on the Optimal Design and Control Performance of interior Permanent Magnet Synchronous Motor for EV/HEV," Hanyang Univ. Ph. D. Dissertation. Feb. 2008.

[5] S. R. MacMinn, T. M. Jahns, "Control Techniques for Improved High-Speed Performance of Interior PM Synchronous Motor Drive," IEEE Trans. Ind. Appl., Vol. IA-27, No. 4, pp. 997-1004, Sep. 1991.

[6] S. Morimoto, M. Sanada, Y. Taketa, "Wide-Speed Operation of Interior Permanent Magnet Synchronous Motors with High-Performance Current Regulator," IEEE Trans. Ind. Appl., Vol. IA-30, No. 4, pp. 920926, Jul. 1994.

[7] S. Morimoto, M. Sanada, Y. Taketa, "Effect and Compensation of Magnetic Saturation in FluxWeakening Controlled Permanent Magnet Synchronous Motor Drive," IEEE Trans. Ind. Appl., Vol. IA-30, No. 6, pp. 1632-1637, Nov. 1994.

[8] E. C. Lovelace, T. M. Jahns, J. H. Lang, "A Saturation Lumped Parameter Model for an Interior PM Synchronous Machine," IEEE Trans. Ind. Appl., Vol. 38, No. 3, pp.645-650, May 2002.

[9] B. Stumberger, G. Stumberger, D. Dolinar, A. Hamler, M. Trlep, "Evaluation of Saturation and CrossMagnetization Effects in Interior Permanent Magnet Synchronous Motor," IEEE Trans. Ind. Appl., Vol. 39, No. 5, pp. 1264-1271, Sep. 2003.

[10] H. Kim, R. D. Lorenz, "Improved Current Regulators for IPM Machine Drives Using On-Line Parameter Estimation," in Proceedings of IEEE IAS Annual Meeting, Pittsburgh, USA, pp.86-91, Oct. 2002.

[11] Y. A. I. Mohamed, T. K. Lee, "Adaptive Self-Tuning MTPA Vector Controller for IPMSM Drive System," IEEE Trans. Energy Convers. Vol. 21, No. 3, pp 636644, Sep. 2006.
[12] Z. Q. Zhu, Y. S. Chen, D. Howe, "Online Optimal Flux-Weakening Control of Permanent Magnet Brushless AC Drives," IEEE Trans. Ind. Appl., Vol. 36, No. 6, pp. 1661-1668, Nov. 2000.

[13] M. N. Uddin, M. A. Rahman, "High Speed Control of IPMSM Drives Using Improved Fuzzy Logic Algorithms," IEEE Trans. Ind. Electron., Vol. 54, No. 1, pp. 190-199, Feb. 2007.

[14] J. L. Shi, T. H. Liu, S. H. Yang, "Nonlinear Controller Design for an Interior Permanent Magnet Synchronous Motor including Field-Weakening Operation," IET Electr. Power Appl., Vol. 1, No. 1, pp. 119-126, Jan. 2007.

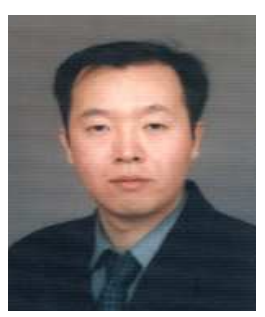

Youn-Hyun. Kim (S'01-M'04) He received the B.S., M.S., Ph. D. degrees in electrical engineering from Hanyang University in 1987, 1989, and 2002, respectively. He worked for LG Industrial System Co. as a Senior Research Engineer from 1989 to 1999 . He is currently a professor in Department of Electrical Engineering, Hanbat National University. His research areas of interest are Motor Drive, Design and Analysis of Machine, and Power Electronics.

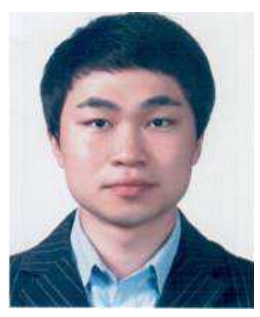

Won-Kyu Kim He received the B.S., M.S. degrees in electrical engineering from National Hanbat University in 2009, 2011, respectively. He has been working for Daedong Movel System Co. as an Assistant Research Engineer from 2010. His research areas of interest are Motor Drive, Control and Design, and Control system of Electric Vehicles.

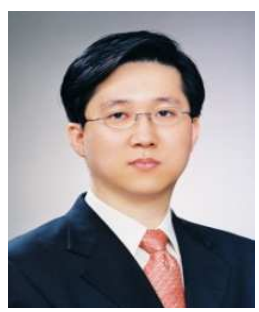

Sol Kim He received B.S, M.S., Ph. D. degrees in electrical engineering from Hanyang University in 1997, 1999, and 2004, respectively. He is currently a professor in department of electrical engineering, Yuhan College. His research interests are motor design and motor drives. 